\title{
The Use of Shoulder Hemiarthroplasty and Humeral Head Resurfacing: A Review of Current Concepts
}

\author{
James C. Widnall ${ }^{1}$, Sujay K. Dheerendra ${ }^{*}, 1$, Robert J. MacFarlane ${ }^{2}$ and Mohammad Waseem ${ }^{2}$ \\ ${ }^{I}$ Department of Trauma \& Orthopaedics, Aintree University Hospital NHS Foundation Trust, Aintree University \\ Hospital, Longmoor Lane, Liverpool, L9 7AL, UK \\ ${ }^{2}$ Department of Trauma \& Orthopaedics, Macclesfield District General Hospital, Victoria Road, Macclesfield, \\ Cheshire, SK10 3BL, UK
}

\begin{abstract}
Since Neer's early work in the 1950s shoulder arthroplasty has evolved as a treatment option for various glenohumeral joint disorders. Both hemiarthroplasty and total shoulder prostheses have associated problems. This has led to further work with regards to potential resurfacing, with the aim of accurately restoring native proximal humeral anatomy while preserving bone stock for later procedures if required. Hemiarthroplasty remains a valuable treatment option in the low demand patient or in the trauma setting. Additional work is required to further define the role of humeral resurfacing, with the potential for it to become the gold standard for younger patients with isolated humeral head arthritis.
\end{abstract}

Keywords: Humeral resurfacing, hemiarthroplasty, glenohumeral osteoarthritis, proximal humerus fracture.

\section{BACKGROUND}

A French surgeon, Paean, was the first to implant a shoulder prosthesis in 1893. It wasn't until Neer's work in the 1950s however that shoulder arthroplasty began to truly develop [1]. His early work with proximal humerus fractures provided him with the experience to use the same concepts to treat shoulder osteoarthritis (OA) [1]. Since then a number of prostheses have been developed for a range of specific circumstances.

Stemmed humeral head replacement, either with or without glenoid replacement has a longstanding history of treatment of glenohumeral joint disorders. Much work has recently gone into developing improved stemmed prostheses, whether for the purpose of hemiarthroplasty or total shoulder arthroplasty [2-4]. Both concepts have had their problems, however, with excessive glenoid wear is associated with the hemiarthroplasty and glenoid component loosening in the total shoulder arthroplasty, in particular resulting in mixed outcomes.

Humeral head resurfacing has developed largely as $\mathrm{s}$ result of advances in the last two decades in hip resurfacing arthroplasty. First generation prostheses relied on cement to ensure accurate and stable positioning. This was bettered by the development of a central stem combined with a hydroxyapatite ongrowth surface to encourage longer term fixation [5,6]. More recent implants have been further enhanced with various size and offset options and cruciate stems to attain rotational stability at the time of insertion [7, 8]. This allows for the surgeon to replicate normal anatomy more closely than before.

*Address correspondence to this author at 36, Raleigh Close, Old Hall, Warrington, WA5 9Q, UK; Tel: 01925573101;

E-mail: sujaykd@yahoo.com
Humeral head resurfacing allows for preservation of bone stock, especially in younger patients who may need further arthroplasty procedures. In addition, a number of complications more readily associated with stemmed arthroplasty procedures, such as excessive bleeding and humeral fracture, are less frequently observed with resurfacing. If complications arise requiring revision surgery (e.g. glenoid arthrosis or implant failure) the lack of a cemented or ingrown stem and the preservation of proximal humeral bone stock allows for a relatively straightforward conversion to total joint arthroplasty [6]. Furthermore, biomechanical studies have shown resurfacing to have greater capacity for accommodating the individual variability in proximal humeral anatomy. Version, head height and offset can all be accounted for and managed with resurfacing prostheses as opposed to stemmed implants [9-12].

\section{ASSESSMENT}

As with all patients in an elective setting, a thorough history and examination is invaluable in order to assess which surgical treatment will offer the best result. Younger patients are more likely to have more complex problems, such as rheumatoid or other systemic inflammatory joint disease, with primary OA being a less frequent cause than in elderly patients. Younger patients may also lead more active life styles with greater functional demands, thus placing increased stress through their implants. Patients' occupation and hobbies will also have an impact on the choice of treatment. With those under fifty years of age more likely to have AVN or post traumatic arthritis, it is important to delineate the specific anatomical area that is the cause of pain. Usually only one side of the glenohumeral joint will be affected [13, 14]. Preserving the other side will have clear benefits to the patient. Radiographs including axillary view will enable evaluation of the glenoid morphology. It has been shown that eccentric wear on the glenoid results in 
poorer outcomes following hemiarthroplasty, with those without glenoid wear exhibiting nearly double the functional improvement noted post operatively in Simple Shoulder Testing $[15,16]$. Computed Tomography (CT) scanning may be required if the quality of the glenoid articular surface is in doubt [17, 18]. If undertaking a revision procedure for prolonged pain, it is necessary to exclude deep infection, with routine blood tests (including inflammatory markers such as erythrocyte sedimentation rate (ESR) and $\mathrm{C}$ reactive protein (CRP)) and consider joint aspirate [19].

\section{INDICATIONS}

Degenerative or inflammatory damage to the glenohumeral joint may warrant the need for surgical intervention. Primary osteoarthritis, avascular necrosis, rheumatoid arthritis and post-traumatic arthritis are the most frequent indications for arthroplasty procedures. Younger patients with more complex pathology, whilst in those over fifty primary OA is the more frequent indication [20]. Unless the patient has suffered a major insult to their rotator cuff, in which case a reverse shoulder replacement may be more appropriate, the surgeon is presented with numerous anatomical replacement options. Resurfacing, hemiarthroplasty, with and without soft tissue glenoid resurfacing, and total shoulder prostheses are all available for use. It is generally accepted that surgical intervention is only indicated once conservative treatment including physical therapy and pharmacological treatments (including both oral agents and intra articular steroids) have been exhausted.

Hemiarthroplasty is a reasonable option in cases of avascular necrosis of the head, without significant glenoid involvement and in rheumatoid arthritis. It is also indicated in the acute setting of proximal humeral fractures that are complex in nature, especially those exhibiting high risk for progressing onto AVN. However, in the elderly patient with significant proximal humeral injury, reverse shoulder arthroplasty is often indicated due to the presence of glenoid wear and poor rotator cuff function.

Humeral resurfacing is best suited to the younger, more active patient whose disease is limited to the humeral head. Osteoarthritis, avascular necrosis and rheumatoid arthritis are frequent indications for humeral resurfacing, providing glenoid morphology is well preserved and the patients is of a suitable age with reasonable bone stock. Rotator cuff arthropathy (with stable biomechanics) and posttraumatic arthritis are also commonly treated with resurfacing arthroplasty. While increasing age is not a contraindication, its impact on the quality of bone should be taken into account. The subchondral surface should be able to support $>60 \%$ of the implant $[6,21,22]$. An intact subscapularis tendon should be present in order to attain anterior stability. If the subscapularis is deficient, the pectoralis major muscle can be transferred in its place [5].

\section{RESULTS}

Since Neer's work in the 1970s various authors have demonstrated noticeable improvements in pain and functional measures following shoulder hemiarthroplasty [23-27]. It has been noted however that these results are dependent on the extent of glenoid wear, intact rotator cuff and reasonable adherence with post operative rehabilitation regimens. A recent Cochrane review reported that significant clinical and functional improvements are seen in patients undergoing hemiarthroplasty surgery for joint degeneration, in terms of visual analogue scale (VAS) pain scores and American Shoulder and Elbow Surgeons (ASES) Shoulder Score [2, 3]. It is worth noting that outcomes for hemiarthroplasty are comparable with those in primary total shoulder arthroplasty in terms of pain, though functional improvement is greater following primary total shoulder arthroplasty. Revision rates and quality of life indicators are also comparable to that of total shoulder prostheses [4]. The efficacy of hemiarthroplasty, when used in the correct setting, is favorable, but should be used with caution in those with high functional demands.

Results of resurfacing arthroplasty compare favourably to those following stemmed prostheses. Levy and Copeland reported their mid-term results of 103 joints in 94 patients, demonstrating a mean Constant score of $93.7 \%$ in those undergoing total joint replacement with head resurfacing, and $73.5 \%$ for those undergoing resurfacing hemiarthroplasty, in patients with primary OA [6]. Inferior results were seen in those who had cuff arthropathy or posttraumatic arthropathy with mean Constant scores at a mean of 6.8 years of $61.3 \%$ and $62.7 \%$ respectively. In a further series, Levy and Copeland reported improved Constant functional scores from a mean of $33.8 \%$ to $94 \%$ for total shoulder replacement with resurfacing and from $40 \%$ to $90 \%$ following resurfacing hemiarthroplasty, at a mean of 7.6 and 4.4 years respectively [21]. A further study of humeral resurfacing in 36 patients under fifty also revealed positive outcomes with VAS scores decreasing from 75 to 13 post operatively. Revision rates for the Copeland resurfacing prosthesis have been quoted between $0-3.0 \%$ [21, 22], with the main indication for revision being implant loosening. Longer term results have been reported in 74 shoulders in 61 patients at a minumum of 20 years [28]. Prosthesis survival was reported as $96 \%$, with $95 \%$ patient satisfaction. Revision rate was $7 / 74$ cases $(9.4 \%)$.

In the coming years results from a range of other implants at mid- and long-term are likely to be reported. At present there is a lack of prospective, randomised, comparative studies examining the results of resurfacing arthroplasty compared with other procdures e.g. total shoulder arthroplasty with stemmed prostheses. This should become the focus for future clinical studies.

\section{COMPLICATIONS}

Prosthetic loosening is one of the more troublesome issues for shoulder surgeons, usually requiring revision surgery. Its prevalence is less of an issue with regards to hemiarthroplasty and hemiresurfacing of the shoulder as it is predominantly the glenoid implant in total joint arthroplasty procedures which are problematic [29, 30]. Humeral component loosening is more common in total shoulder replacements when compared to hemiarthroplasty [31]. Lucent lines of $>2 \mathrm{~mm}$ in thickness or evidence of subsidence are considered significant, and clinical correlation is required before revision surgery is considered.

Glenohumeral instability may occur as a result of soft tissue deficiency or laxity, or component malpositioning, wear, or incorrect sizing. Anterior instability is more 
common, accounting for $80 \%$ of instability after shoulder arthroplasty [32]. Instability can be multifactorial. Soft tissues such as subscapularis and anterior capsule abnormalities can have a detrimental effect as can a humeral implant that is over sized, placed anteriorly or in improper retroversion $\left(<20^{\circ}\right)$ [33].

Humeral periprosthetic fracture is observed either at the time of implantation or following the postoperative period. Osteoporosis, female sex, increased age and increased falls risk all lead to a higher probability of a periprosthetic fracture [34]. Fractures are classified according to the system devised by Wright and Cofield [35] (Table 1). Conservative treatment is usually indicated for type $\mathrm{C}$ and long spiral or oblique fracture patterns. Type A and short type B fractures frequently require surgical intervention, with internal fixation, with or without implant exchange, generally required.

Table 1. Periprosthetic Humeral Fractures Classification System (Humeral Fractures After Shoulder Arthroplasty. JBJS Am 77: 1340-1346)

\begin{tabular}{|c|c|}
\hline Type & Description \\
\hline A & $\begin{array}{l}\text { Fracture at the tip of the stem, extending more } \\
\text { proximally than one third of the length of the stem }\end{array}$ \\
\hline B & $\begin{array}{l}\text { Fracture at the tip of the stem with } \\
\text { less than one third proximal extension }\end{array}$ \\
\hline $\mathrm{C}$ & Fracture distal to the implant \\
\hline
\end{tabular}

Insufficient cuff repair/fixation, mal-rotation of humeral implant and multiple surgical procedures may all lead to potential rotator cuff problems. If cuff pathology exists, it is likely to reduce the life of the implant due to asymmetric loading and increased wear [36-38]. Postoperative deep infection, whilst rare, can be a devastating complication. Rates for infection are reported as less than $1 \%$ in primary resurfacing procedures $[6,29]$. In shoulder arthroplasty in general, infection rates at 10 and 20 years have been reported as $1.5 \%$ and $2.8 \%$ respectively, with males and younger patients at greater risk [39] Staphylococcus aureus is the most common causative organism. The risk of infection is greater in those with immunosuppression, diabetes, systemic inflammatory or autoimmune disease, intra-articular injections and poor nutrition [40]. Most superficial wound infections settle with systemic antibiotic therapy. Persistent deep infection, in those with raised acute phase reactants and a positive joint aspirate confirming the diagnosis, usually requires revision surgery [41].

In both hemiarthroplasty and hemiresurfacing, glenoid wear is known to be a significant cause of poor outcome. Implant survival rates have been described as low as $82 \%$ and $75 \%$ after 10 and 20 years respectively [26]. In a further study, a meta-analysis of over 2000 patients, quoted the revision rate to be $10.2 \%$ [42]. This is compared to a $6.5 \%$ revision rate for total shoulder arthroplasties. This has led to many authors favoring a total shoulder prosthesis over that of a hemiarthroplasty in the treatment of glenohumeral disorders [3, 43]. Biological glenoid resurfacing is gaining popularity, but early results show a trend that suggests glenoid wear is not prevented by soft tissue interposition
[44]. Many argue that the greater chance for reconstitution of normal proximal humerus anatomy after resurfacing leads it to lesser risk of progressive glenoid wear.

\section{CONCLUSION}

Recent resurfacing results have been reported to equal those of the more conventional hemiarthroplasty procedures [6]. Humeral resurfacing confers considerable advantages in terms of to preservation of bone stock, enabling restoration of glenohumeral anatomy, and relative ease of revision surgery, when compared to a stemmed prosthesis. For now total or reverse shoulder arthroplasty remains the procedure of choice for many upper limb surgeons treating glenohumeral joint disease. Hemiarthroplasty is in general reserved for those patients who will not look to exceed the post operative function that the implant is capable of. Younger patients who are likely to require 2 or more implants should be considered for resurfacing arthoplasty to preserve bone stock and enable relatively straightforward revision surgery. In the coming years, longer term prospective, comparative data will allow surgeons to make more informed choices regarding the ideal implant for their patients.

\section{ABBREVIATIONS}

$\begin{array}{ll}\text { ASES } & =\text { American shoulder and elbow surgeons score } \\ \text { AVN } & =\text { Avascular necrosis } \\ \text { CRP } & =\text { C reactive protein } \\ \text { CT } & =\text { Computed tomography } \\ \text { ESR } & =\text { Erythrocyte sedimentation rate } \\ \text { OA } & =\text { Osteoarthritis } \\ \text { RA } & =\text { Rheumatoid arthritis } \\ \text { VAS } & =\text { Visual analogue scale }\end{array}$

\section{CONFLICT OF INTEREST}

The authors confirm that this article content has no conflict of interest.

\section{ACKNOWLEDGEMENTS}

Declared none.

\section{REFERENCES}

[1] Neer $2^{\text {nd }}$ CS, Watson KC, Stanton FJ. Recent experience in total shoulder replacement. J Bone Joint Surg Am 1982; 64: 319-37.

[2] Lo IK, Litchfield RB, Griffin S, Faber K, Patterson SD, Kirkley A. Quality-of-life outcome following hemiarthroplasty or total shoulder arthroplasty in patients with osteoarthritis. A prospective, randomized trial. J Bone Joint Surg 2005; 87(10): 2178-85.

[3] Gartsman GM, Roddey TS, Hammerman SM. Shoulder arthroplasty with or without resurfacing of the glenoid in patients who have osteoarthritis. J Bone Joint Surg Am 2000; 82(1): 26-34.

[4] Singh JA, Sperling J, Buchbinder R, McMaken K. Surgery for shoulder osteoarthritis. Cochrane Database Syst Rev 2010; (10): CD008089.

[5] Fink B, Singer J, Lamla U, Rüther W. Surface replacement of the humeral head in rheumatoid arthritis. Arch Orthop Trauma Surg 2004; 124: 366-73

[6] Levy O, Copeland SA. Cementless surface replacement arthroplasty of the shoulder. 5- to 10-year results with the Copeland Mark-2 prosthesis. J Bone Joint Surg Br 2001; 83: 213-22.

[7] Boileau P, Walch G. The three-dimensional geometry of the proximal humerus. Implications for surgical technique and prosthetic design. J Bone Joint Surg Br 1997; 79: 857-65. 
[8] Iannotti JP, Gabriel JP, Schneck SL, Evans BG, Misra S. The normal glenohumeral relationships. An anatomical study of one hundred and forty shoulders. J Bone Joint Surg Am 1992; 74: 491500 .

[9] Pearl ML. Proximal humeral anatomy in shoulder arthroplasty: implications for prosthetic design and surgical technique. J Shoulder Elbow Surg 2005; 14(1 suppl S): 99S-104S.

[10] Pearl ML, Kurutz S, Robertson DD, Yamaguchi K. Geometric analysis of selected press fit prosthetic systems for proximal humeral replacement. J Orthop Res 2002; 20: 192-7.

[11] Thomas SR, Sforza G, Levy O, Copeland SA. Geometrical analysis of Copeland surface replacement shoulder arthroplasty in relation to normal anatomy. J Shoulder Elbow Surg 2005; 14: 186-92.

[12] Hammond G, Tibone JE, McGarry MH, Jun BJ, Lee TQ. Biomechanical comparison of anatomic humeral head resurfacing and hemiarthroplasty in functional glenohumeral positions. J Bone Joint Surg Am 2012; 94(1): 68-76.

[13] Kerr BJ, McCarty EC. Outcome of arthroscopic d'ebridement is worse for patients with glenohumeral arthritis of both sides of the joint. Clin Orthop Relat Res 2008; 466: 634-8.

[14] Cameron BD, Galatz LM, Ramsey ML, Williams GR, Iannotti JP. Non-prosthetic management of grade IV osteochondral lesions of the glenohumeral joint. J Shoulder Elbow Surg 2002; 11: 25-32.

[15] Levine WN, Djurasovic M, Glasson JM, Pollock RG, Flatow EL, Bigliani LU. Hemiarthroplasty for glenohumeral osteoarthritis: results correlated to degree of glenoid wear. J Shoulder Elbow Surg 1997; 6: 449-54.

[16] Hettrich CM, Weldon E $3^{\text {rd }}$, Boorman RS, Parsons IM $4^{\text {th }}$, Matsen FA $3^{\text {rd }}$. Preoperative factors associated with improvements in shoulder function after humeral hemiarthroplasty. J Bone Joint Surg Am 2004; 86: 1446-51.

[17] Nyffeler RW, Jost B, Pfirrmann CW, Gerber C. Measurement of glenoid version: conventional radiographs versus computed tomography scans. J Shoulder Elbow Surg 2003; 12: 493-6.

[18] Bryce CD, Davison AC, Lewis GS, Wang L, Flemming DJ, Armstrong AD. Two dimensional glenoid version measurements vary with coronal and sagittal scapular rotation. J Bone Joint Surg Am 2010; 92: 692-9.

[19] Dodson CC, Craig EV, Cordasco FA, et al. Propionibacterium acnes infection after shoulder arthroplasty: a diagnostic challenge. J Shoulder Elbow Surg 2010; 19: 303-7.

[20] Groh GI, Williams GR, Jarman RN, Rockwood CA Jr. Treatment of complications of shoulder arthrodesis. J Bone Joint Surg Am 1997; 79: 881-7.

[21] Levy O, Copeland SA. Cementless surface replacement arthroplasty for osteoarthritis of the shoulder. J Shoulder Elbow Surg 2004; 13: 266-71.

[22] Levy O, Funk L, Sforza G, Copeland SA. Copeland surface replacement arthroplasty of the shoulder in rheumatoid arthritis. J Bone Joint Surg Am 2004; 86: 512-8.

[23] Norris TR, Iannotti JP. Functional outcome after shoulder arthroplasty for primary osteoarthritis: a multicenter study. J Shoulder Elbow Surg 2002; 11: 130-5.

[24] Hattrup SJ, Cofield RH. Osteonecrosis of the humeral head: results of replacement. J Shoulder Elbow Surg 2000; 9: 177-82.

[25] Rispoli DM, Sperling JW, Athwal GS, Schleck CD, Cofield RH. Humeral head replacement for the treatment of osteoarthritis. J Bone Joint Surg Am 2006; 88: 2637-44.
[26] Sperling JW, Cofield RH, Rowland CM. Minimum fifteen-year follow-up of Neer hemiarthroplasty and total shoulder arthroplasty in patients aged fifty years or younger. J Shoulder Elbow Surg 2004; 13: 604-13.

[27] Wirth MA, Tapscott RS, Southworth C, Rockwood CA Jr. Treatment of glenohumeral arthritis with a hemiarthroplasty: a minimum five-year follow-up outcome study. J Bone Joint Surg Am 2006; 88: 964-73.

[28] Pritchett JW. Long-term results and patients satisfaction following shoulder resurfacing. J Shoulder Elbow Surg 2011; 20(5): 771-7

[29] Bohsali KI, Wirth MA, Rockwood CA Jr. Complications of total shoulder arthroplasty. J Bone Joint Surg Am2006; 88: 2279-92.

[30] Deshmukh AV, Koris M, Zurakowski D, Thornhill TS. Total shoulder arthroplasty: long-term survivorship, functional outcome, and quality of life. J Shoulder Elbow Surg 2005; 14: 471-9.

[31] Sanchez-Sotelo J, O'Discroll SW, Torchia ME, Cofield RH, Rowland CM Radiographic assessment of cemented humeral components in shoulder arthroplasty. J Shoulder Elbow Surg 2001; 10: 526-31.

[32] Warren RF, Coleman SH, Dines JS. Instability after arthroplasty: the shoulder. J Arthroplasty 2002; 17: 28-31.

[33] Wirth MA, Rockwood CA Jr. Complications of total shoulderreplacement arthroplasty. J Bone Joint Surg Am 1996; 78: 603-16.

[34] McDonough EB, Crosby LA. Periprosthetic fractures of the humerus. Am J Orthop 2005; 34(12): 586-91.

[35] Wright TW, Cofield RH. Humeral fractures after shoulder arthroplasty. J Bone Joint Surg Am 1995; 77: 1340-46.

[36] Brems JJ. Complications of shoulder arthroplasty: infections, instability, and loosening. Instr Course Lect 2002; 51: 29-30.

[37] Bonutti PM, Hawkins RJ. Fracture of the humeral shaft associated with total replacement arthroplasty of the shoulder. A case report. J Bone Joint Surg Am 1992; 74: 617-8.

[38] Miller BS, Joseph TA, Noonan TJ, Horan MP, Hawkins RJ. Rupture of the subscapularis tendon after shoulder arthroplasty: diagnosis, treatment, and outcome. J Shoulder Elbow Surg 2005; 14: 492-6.

[39] Singh JA, Sperling JW, Schleck C, Harmsen WS, Cofield RH. Periprosthetic infections after total shoulder arthroplasty: A 33 year perspective. J Shoulder Elbow Surg 2012; 21(11): 1534-41.

[40] Rosenberg N, Neuann L, Modi A, Mersich IJ, Wallace AW. Improvements in survival of the uncemented Nottingham total shoulder prosthesis: a prospective comparative study. BMC Musculoskelet Disord 2007; 8: 76.

[41] Sperling JW, Kozak TK, Hanssen AD, Cofield RH. Infection after shoulder arthroplasty. Clin Orthop Relat Res 2001; 382: 206-16.

[42] Radnay CS, Setter KJ, Chambers L, Levine WN, Bigliani LU, Ahmad CS. Total shoulder replacement compared with humeral head replacement for the treatment of primary glenohumeral osteoarthritis: a systematic review. J Shoulder Elbow Surg 2007; 16: 396-402.

[43] Edwards TB, Kadakia NR, Boulahia A, et al. A comparison of hemiarthroplasty and total shoulder arthroplasty in the treatment of primary glenohumeral osteoarthritis: results of a multicenter study. J Shoulder Elbow Surg 2003; 12: 207-13.

[44] Burkhead WZ, Krishnan SG, Lin KC. Biologic resurfacing of the arthritic glenohumeral joint: historical review and current applications. J Shoulder Elbow Surg 2007; 16: S248-53. 